Article

\title{
Fabrication of Low Cost and Low Temperature Poly-Silicon Nanowire Sensor Arrays for Monolithic Three-Dimensional Integrated Circuits Applications
}

\author{
Siqi Tang ${ }^{1,2}$, Jiang Yan ${ }^{1, *}$, Jing Zhang ${ }^{1}$, Shuhua Wei ${ }^{1}$, Qingzhu Zhang ${ }^{2} \oplus$, Junjie Li $^{2}{ }^{\circledR}$, \\ Min Fang ${ }^{1}$, Shuang Zhang ${ }^{1}$, Enyi Xiong ${ }^{1}$, Yanrong Wang ${ }^{1}$, Jianglan Yang ${ }^{3}$, \\ Zhaohao Zhang ${ }^{2, *}$, Qianhui Wei ${ }^{3, *}$, Huaxiang Yin ${ }^{2,4}{ }^{-}$, Wenwu Wang ${ }^{2,4}$ and Hailing $\mathrm{Tu}^{3}$ \\ 1 School of Information Science and Technology, North China University of Technology, \\ Beijing 100144, China; tangsiqi@ime.ac.cn (S.T.); zhangj@ncut.edu.cn (J.Z.); \\ weishuhua@ncut.edu.cn (S.W.); fangmin@ime.ac.cn (M.F.); zhangshuang2020@ime.ac.cn (S.Z.); \\ xiongenyi@ime.ac.cn (E.X.); wangyanrong@ncut.edu.cn (Y.W.) \\ 2 Advanced Integrated Circuits R\&D Center, Institute of Microelectronic of the Chinese Academy of Sciences, \\ Beijing 100029, China; zhangqingzhu@ime.ac.cn (Q.Z.); lijunjie@ime.ac.cn (J.L.); \\ yinhuaxiang@ime.ac.cn (H.Y.); wangwenwu@ime.ac.cn (W.W.) \\ 3 State Key Laboratory of Advanced Materials for Smart Sensing, General Research Institute for \\ Nonferrous Metals, Beijing 101402, China; yangjianglan955295@hotmail.com (J.Y.); tuhl@grinm.com (H.T.) \\ 4 School of Microelectronics, University of Chinese Academy of Sciences, Beijing 100049, China \\ * Correspondence: yanjiang@ncut.edu.cn (J.Y.); zhangzhohao@ime.ac.cn (Z.Z.); \\ weiqianhui@grinm.com (Q.W.); Tel.: +86-010-8880-2600 (J.Y.)
}

Received: 4 November 2020; Accepted: 7 December 2020; Published: 11 December 2020

\begin{abstract}
In this paper, the poly-Si nanowire (NW) field-effect transistor (FET) sensor arrays were fabricated by adopting low-temperature annealing $\left(600^{\circ} \mathrm{C} / 30 \mathrm{~s}\right)$ and feasible spacer image transfer (SIT) processes for future monolithic three-dimensional integrated circuits (3D-ICs) applications. Compared with other fabrication methods of poly-Si NW sensors, the SIT process exhibits the characteristics of highly uniform poly-Si NW arrays with well-controlled morphology (about $25 \mathrm{~nm}$ in width and $35 \mathrm{~nm}$ in length). Conventional metal silicide and implantation techniques were introduced to reduce the parasitic resistance of source and drain (SD) and improve the conductivity. Therefore, the obtained sensors exhibit $>10^{6}$ switching ratios and $965 \mathrm{mV} / \mathrm{dec}$ subthreshold swing (SS), which exhibits similar results compared with that of SOI Si NW sensors. However, the poly-Si NW FET sensors show the $\mathrm{V}_{\text {th }}$ shift as high as about $178 \pm 1 \mathrm{mV} / \mathrm{pH}$, which is five times larger than that of the SOI Si NW sensors. The fabricated poly-Si NW sensors with $600{ }^{\circ} \mathrm{C} / 30$ s processing temperature and good device performance provide feasibility for future monolithic three-dimensional integrated circuit (3D-IC) applications.
\end{abstract}

Keywords: silicon nanowire (Si NW); monolithic three-dimensional integrated circuits (M3D-ICs); spacer image transfer (SIT); sensitivity

\section{Introduction}

In recent years, the application of semiconductor field-effect transistors (FET) sensors have attracted a lot of attention because of their ability to translate the interaction with target molecules on the FET surface to an electrical signal directly [1-4]. Silicon nanowires (Si NW) sensors have been considered as one of the most promising candidates for biochemical sensors [5-9], due to their large surface to volume (S/V) ratio, high sensitivity, and good biocompatibility $[10,11]$. In recent years, 
Si NW field-effect-transistor (FET) sensors have been used for the very high sensitivity detection of pH [12-14], gases [15-17] and DNA [18-20]. However, the conventional fabrication process with silicon-on-insulator (SOI) materials is complex and high-cost, and the nanometer patterns are usually formed by traditional low-efficiency electron beam lithography (EBL) process, which does not meet the demands of future mass production with a low cost and low efficiency. The spacer image transfer (SIT) process (also named self-aligned double or quadruple patterning) could achieve nanometer array with high efficiency and low cost, which are widely used in foundries [21-23]. In addition, there are no reports on the design or fabrication of Si NW sensors for monolithic three-dimensional integrated circuits (3D-ICs) application, which is one of the most convincing candidates for future application (see Figure 1). In order to achieve better performance of the system, the fabrication of top devices (Si NW sensor) usually need low-temperature processes to avoid a degradation on characteristics of bottom circuits (logic circuits and memory in Figure 1) [24]. However, there are no reports on the design or fabrication of Si NW sensor for monolithic 3D-ICs application.

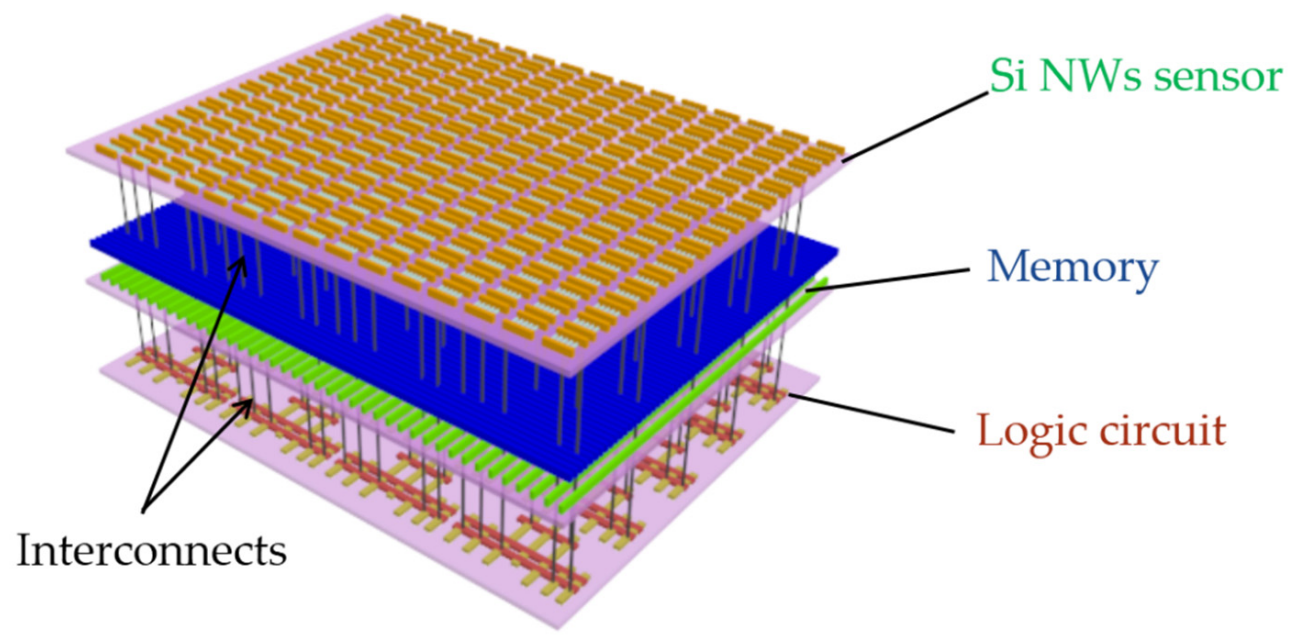

Figure 1. Illustration of monolithic three-dimensional integrated circuits (3D-ICs): bottom logic circuits; middle memory and top silicon nanowire (Si NW) sensors.

In this paper, poly-silicon NW sensors with low cost and high efficiency are designed and fabricated using advanced spacer image transfer (SIT) [22-24] and low-temperature silicide techniques for monolithic 3D-IC application. The highest annealing temperature is not over $600{ }^{\circ} \mathrm{C}$, which overcomes the problems of overheating the bottom transistor and the wires. The achieved poly-silicon NW sensors have good electrical properties, such as over six orders of magnitude in on-off ratio and $932 \mathrm{mV} / \mathrm{dec}$ of subthreshold swing (SS) by bias back-gate voltages.

\section{Materials and Methods}

Two types of Si NW sensors (poly-silicon and silicon-on-insulator (SOI)) were designed and fabricated, and the detailed fabrication flow is illustrated in Figure 2. The poly-silicon NW sensors were manufactured on p-type $200 \mathrm{~mm} \mathrm{Si} \mathrm{(100)} \mathrm{silicon} \mathrm{wafers} \mathrm{(see} \mathrm{Figure} \mathrm{2a):} \mathrm{Firstly,} 145 \mathrm{~nm} \mathrm{SiO} 2$ and $40 \mathrm{~nm}$ poly-silicon were deposited, respectively (see Figure $2 b$ ). The SOI Si NW sensors were manufactured on $200 \mathrm{~mm}$ SOI wafers featured with a 145-nm-thick buried oxide layer (BOX) and a 40-nm-thick top silicon layer. The fabrication process of the two types of devices was all the same in the flowing steps. During the fabrication of the Si NWs, a spacer image transfer (SIT) technology was chosen to form NW arrays patterns with high efficiency [25-27], and the detailed fabrication process flow is described as follows: sequential multi-layer $\mathrm{SiO}_{2}$ /amorphous $\mathrm{Si}(\alpha-\mathrm{Si}) / \mathrm{Si}_{3} \mathrm{~N}_{4}$ films were deposited (see Figure $2 \mathrm{c}$ ). Next, the conventional photolithography process (i-line) and dry etching processes were used to form rectangular arrays of $\mathrm{Si}_{3} \mathrm{~N}_{4}$ and $\alpha$-Si films (see Figure $2 \mathrm{~d}$ ). The top $\mathrm{Si}_{3} \mathrm{~N}_{4}$ hard masks (HMs) were removed by a hot $\mathrm{H}_{3} \mathrm{PO}_{4}$ solution at $140{ }^{\circ} \mathrm{C}$ (see Figure 2e). A $30 \mathrm{~nm} \mathrm{Si} \mathrm{N}_{4}$ film was deposited by 
plasma-enhanced chemical vapor deposition (PECVD) approach and then the corresponding $\mathrm{Si}_{3} \mathrm{~N}_{4}$ reactive ion etching (RIE) was performed to form two $\mathrm{SiN}_{x}$ spacers on both sides of $\alpha$-Si (see Figure $2 \mathrm{f}, \mathrm{g}$ ). The $\alpha$-Si material between two $\mathrm{Si}_{3} \mathrm{~N}_{4}$ spacers was removed by tetramenthylammonium hydroxide (TMAH) (see Figure 2h). In order to obtain $\mathrm{Si} \mathrm{NW}$ arrays, dry etching processes of $\mathrm{SiO}_{2}$ and $\mathrm{Si}$ were carried out, respectively (see Figure 2h). Afterward, the top HMs were removed using hot phosphoric acid and diluted hydrofluoroacid (DHF) solution, respectively (see Figure 2i). After the Si NW formation, a 5-nm-thick $\mathrm{SiO}_{2}$ was deposited on the Si NW followed by the deposition of a thick layer of $\mathrm{Si}_{3} \mathrm{~N}_{4}$ (see Figure $2 \mathrm{j}, \mathrm{k}$ ). The $\mathrm{Si}_{3} \mathrm{~N}_{4}$ film was etched by dry etching processes. A nickel platinum alloy $\left(\mathrm{Ni}_{0.95} \mathrm{Pt}_{0.05}\right)$ was used to form metal silicide in the source and drain regions to reduce the parasitic of Si nanowires (see Figure 2l,m). Afterward, $\mathrm{BF}^{2+}$ ions with a heavy dose and low energy were implanted into the top silicided Si NWs and activated by low temperature rapid thermal annealing (RTA) to form Schottky barrier source and drain (SBSD) (about $600{ }^{\circ} \mathrm{C} / 30 \mathrm{~s}$ annealing). For a better combination, the aluminum electrode was prepared by a sputtering process and the RIE process was performed (see Figure 2n,o). Subsequently, a layer of thick $\mathrm{SiO}_{2}$ was deposited, and the source drain contact holes were opened by photolithography and etching processes (see Figure 2p,q). Finally, the gate with different channel lengths $(5,10$ and $15 \mu \mathrm{m})$ was defined by photolithography and the open gate trench of the sensor to expose the sensitive area was achieved by RIE processes. The bounding of SD contact was carried out and a layer of 20-nm-thick $\mathrm{HfO}_{2}$ was deposited on the surface of the device (see Figure 2r). Figure $2 \mathrm{~s}$ is a schematic top view of the device. Except for the source drain and gate trench of the devices, other areas were covered by a thick $\mathrm{SiO}_{2}$, which helps to improve the stability and reliability of the solution.

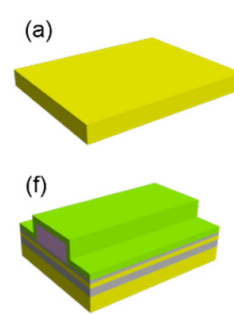

(k)

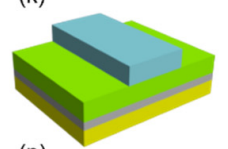

(p)

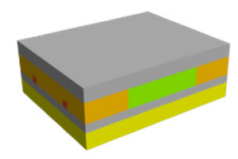

(b)

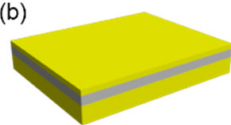

(g)

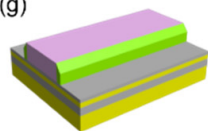

(I)

(q)

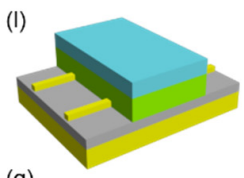

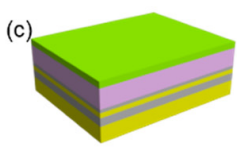

(h)

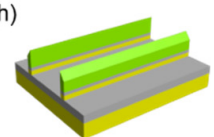

(m)

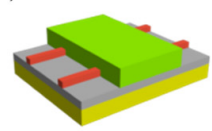

(r)

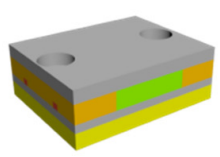

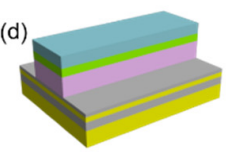

(i)

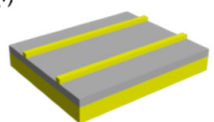

(n)

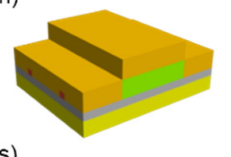

(s)

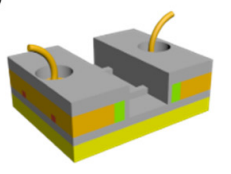

(e)

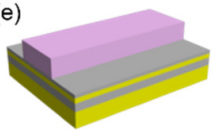

(j)

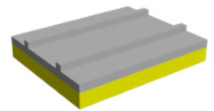

(o)

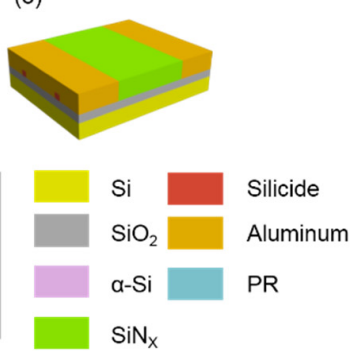

Figure 2. Fabrication flow of Si NW sensors. (a) $200 \mathrm{~mm}$ a p-type (100) silicon wafers, (b) deposition of $\mathrm{SiO}_{2}$ and $\alpha$-Si films, (c) deposition of multi-layer $\mathrm{SiO}_{2} / \alpha-\mathrm{Si}_{/} / \mathrm{Si}_{3} \mathrm{~N}_{4}$ films, (d) conventional lithography and reactive ion etching (RIE) of $\mathrm{Si}_{3} \mathrm{~N}_{4} / \alpha-\mathrm{Si}$, (e) removal of photoresist (PR) and $\mathrm{Si}_{3} \mathrm{~N}_{4}$ hard mask, (f) deposited of $\mathrm{Si}_{3} \mathrm{~N}_{4}$ thin film, (g) anisotropic RIE of $\mathrm{Si}_{3} \mathrm{~N}_{4}$ to form nanometer $\mathrm{Si}_{3} \mathrm{~N}_{4}$ spacers, (h) remove the $\alpha$-Si and $\mathrm{RIE} \mathrm{SiO}_{2}$ and $\mathrm{Si}$ films, (i) removal of top hard masks (HMs), (j) deposition of $5 \mathrm{~nm} \mathrm{SiO}_{2}$ film, (k) deposition of $\mathrm{Si}_{3} \mathrm{~N}_{4}$ and i-line lithography, (l) RIE of $\mathrm{Si}_{3} \mathrm{~N}_{4},(\mathbf{m})$ RIE of $\mathrm{Si}_{3} \mathrm{~N}_{4}$ and forms metal silicide, (n) sputter metal, (o) RIE of metal, (p) deposition of $\mathrm{HfO}_{2}$ film, (q) formation of source and drain contact hole, (r) formation of Si NW channel and bonding and (s) top view of the designed $\mathrm{Si}$ NW sensors.

The cross-sectional views and top views of the device's structures were observed using S-5500 and S-4800 scanning electron microscopes (SEM, Hitachi, Tokyo, Japan), respectively. The cross-sectional profiles of the final device were performed using transmission electron microscopy (TEM, FEI Talos, Brno, Czech) and energy-dispersive X-ray spectroscopy (EDX, FEI Talos, Brno, Czech). The electrical 
characterization was performed using a B1500A (Keysight, Santa Rosa, CA, USA) semiconductor parameter analyzer.

\section{Results and Discussion}

The images of the fabricated poly-Si NWs sensors by the SIT process are shown in Figure 3. Figure 3a,b shows top views of poly-Si NW arrays by SEM measurement. As can been seen from the images, highly uniform poly-Si NW arrays without any landing pads are achieved. The achieved poly-Si NW arrays using the SIT approach have high efficiency, low cost and smaller sizes compared with that of fabricated using the EBL process. Figure $3 c$ shows a cross-sectional view of poly-Si NWs. Contrasted with previous work [28,29], the dimensions and the morphology of the fabricated Si NW arrays are well controlled and extraordinarily small, theoretically providing higher sensitivity for the fabricated poly-Si NW sensor. Figure 3d,e shows top views of poly-Si NW sensors arrays. The length of the electrode is $2 \mathrm{~mm}$; the gate lengths ( $\mathrm{L}_{\mathrm{Gs}}$ ) of poly-Si NW FETs are $5 \mu \mathrm{m}, 10 \mu \mathrm{m}$, and $15 \mu \mathrm{m}$, respectively. The sensor current is increased and the device's variations are reduced for the multi-channel poly-Si NW sensors.
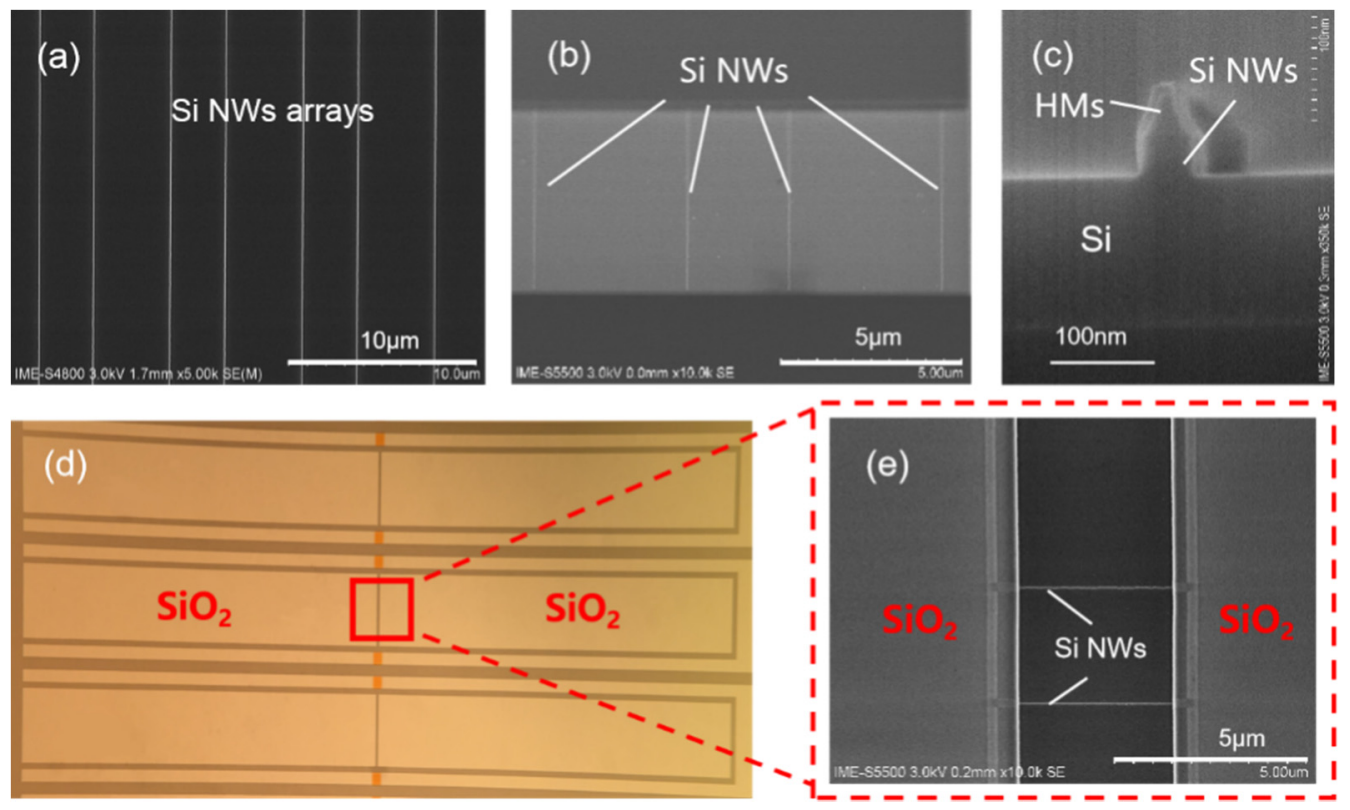

Figure 3. Images of poly-Si NW sensors. (a,b) SEM images of poly-Si NW array in top view, (c) cross-sectional SEM image of poly-Si NWs, (d) top view of poly-Si NW arrays sensor by optical microscope, (e) SEM image of the final poly-Si NW arrays sensor in top view.

Figure 4 shows the cross-sectional TEM image and the electron scattering spectrum (EDS) elemental mappings of the poly-Si NWs channel. According to the TEM image, the thicknesses of $\mathrm{HfO}_{2} / \mathrm{SiO}_{2}$ layers are $19.34 \mathrm{~nm}$ and $5.25 \mathrm{~nm}$, respectively. The sizes of the well-controlled regular rectangle poly-Si NW is about $25 \mathrm{~nm}$ in width and $35 \mathrm{~nm}$ in length. Furthermore, the EDS analysis of Hf, O, poly-Si, and $\mathrm{N}$ elements demonstrates that the $\mathrm{HfO}_{2}$ and $\mathrm{SiO}_{2}$ films are very uniform and the interfaces are clear and flat without inter-diffusion. The well-controlled insulation layer could reduce the leakage current from liquid to device, providing a robust detection environment in the liquid.

Initial measurements of transfer and output curves $\left(\mathrm{I}_{\mathrm{D}}-\mathrm{V}_{\mathrm{G}}\right.$ and $\left.\mathrm{I}_{\mathrm{D}}-\mathrm{V}_{\mathrm{D}}\right)$ were performed by applying a bias gate voltage. In the measurement of the $\mathrm{I}_{D}-\mathrm{V}_{G}$ curve, $\mathrm{I}_{\mathrm{D}}$ was measured at constant drain voltages $\left(\mathrm{V}_{\mathrm{D}}=-0.2 \mathrm{~V},-1.2 \mathrm{~V},-2.2 \mathrm{~V}\right)$, and the gate voltage was swept from 0 to $-30 \mathrm{~V}$. In the measurement of the $I_{D}-V_{D}$ curves, the drain current was measured at constant gate voltages ( $V_{G}$ from 0 to $-20 \mathrm{~V}$ with a $-2 \mathrm{~V}$ step), and the $\mathrm{V}_{\mathrm{D}}$ was swept from 0 to $-5 \mathrm{~V}$ with a $-0.2 \mathrm{~V}$ step. 

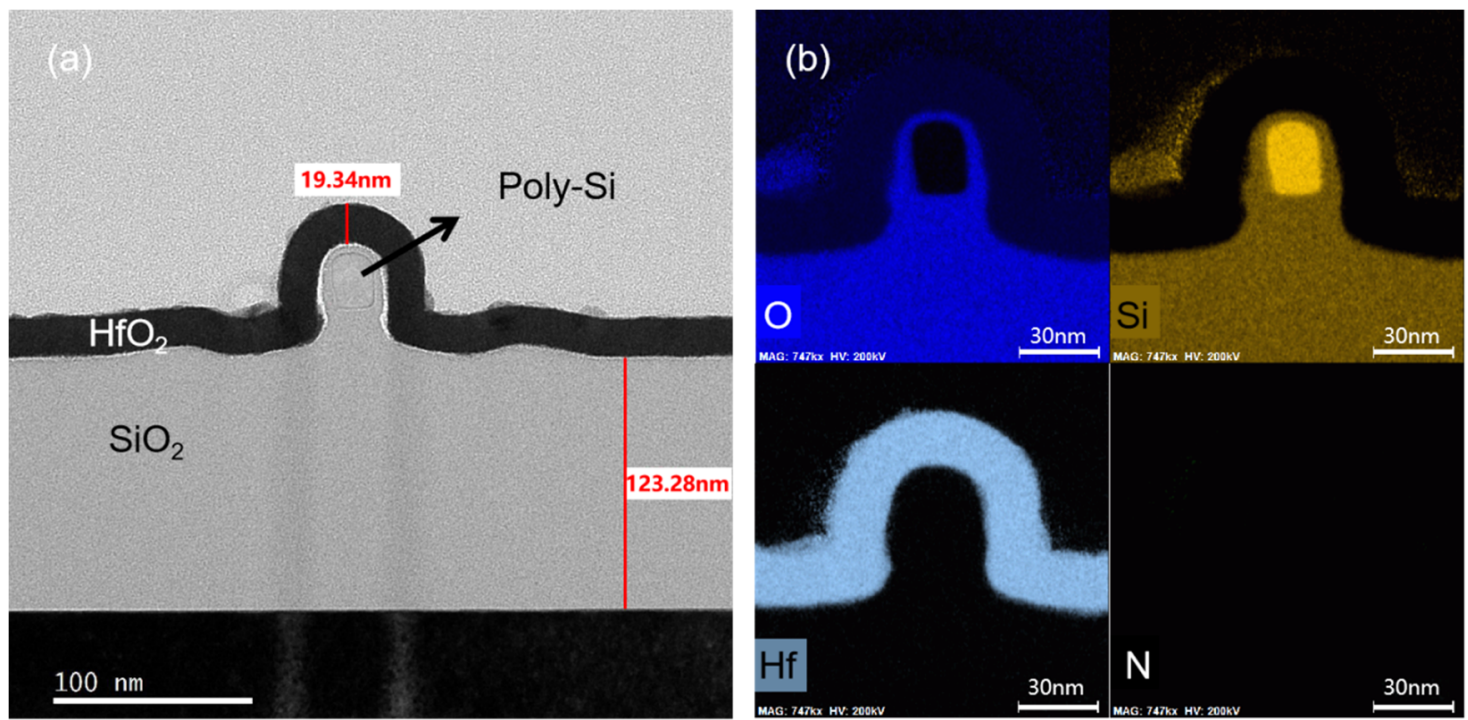

Figure 4. (a) TEM image of poly-Si NW channel of the device, (b) EDS elemental mappings of O, Si, Hf and $\mathrm{N}$, respectively.

The $\mathrm{I}_{\mathrm{D}}-\mathrm{V}_{\mathrm{G}}$ and $\mathrm{I}_{\mathrm{D}}-\mathrm{V}_{\mathrm{D}}$ curves by bias gate voltages of the p-type poly-Si NW sensors are shown in Figure 5. Figure $5 \mathrm{a}-\mathrm{c}$ shows typical $\mathrm{I}_{\mathrm{D}}-\mathrm{V}_{\mathrm{G}}$ curves of $5-\mu \mathrm{m}-\mathrm{L}_{\mathrm{G}}, 10-\mu \mathrm{m}-\mathrm{L}_{\mathrm{G}}$ and $15-\mu \mathrm{m}-\mathrm{L}_{\mathrm{G}}$ poly-Si NW devices, respectively. As can be seen from the images, smooth and uniform p-type MOSFET curves were achieved for the sensors fabricated at low temperature. The $\mathrm{I}_{\mathrm{on}} / \mathrm{I}_{\mathrm{off}}$ ratios of poly-Si NW devices with the $5-\mu \mathrm{m}-\mathrm{L}_{\mathrm{G}}, 10-\mu \mathrm{m}-\mathrm{L}_{\mathrm{G}}$ and $15-\mu \mathrm{m}-\mathrm{L}_{\mathrm{G}}$ are $5.68 \times 10^{6}, 2.84 \times 10^{6}$ and $2.31 \times 10^{6}$, respectively. The corresponding extracted values of subthreshold swing (SS) are estimated to be $1070 \mathrm{mV} / \mathrm{dec}$, $965 \mathrm{mV} / \mathrm{dec}$ and $956 \mathrm{mV} / \mathrm{dec}$, respectively. Figure $5 \mathrm{~d}$ depicts the $\mathrm{I}_{\mathrm{D}}-\mathrm{V}_{\mathrm{D}}$ curves of poly-Si NW device $10-\mu \mathrm{m}-\mathrm{L}_{\mathrm{G}}$. The drain current increases with increasing $\mathrm{V}_{\mathrm{G}}$ bias, implying that the carrier's concentration inside Si NWs can be linearly adjusted, and devices prepared at low temperatures exhibit good FET electrical performance.
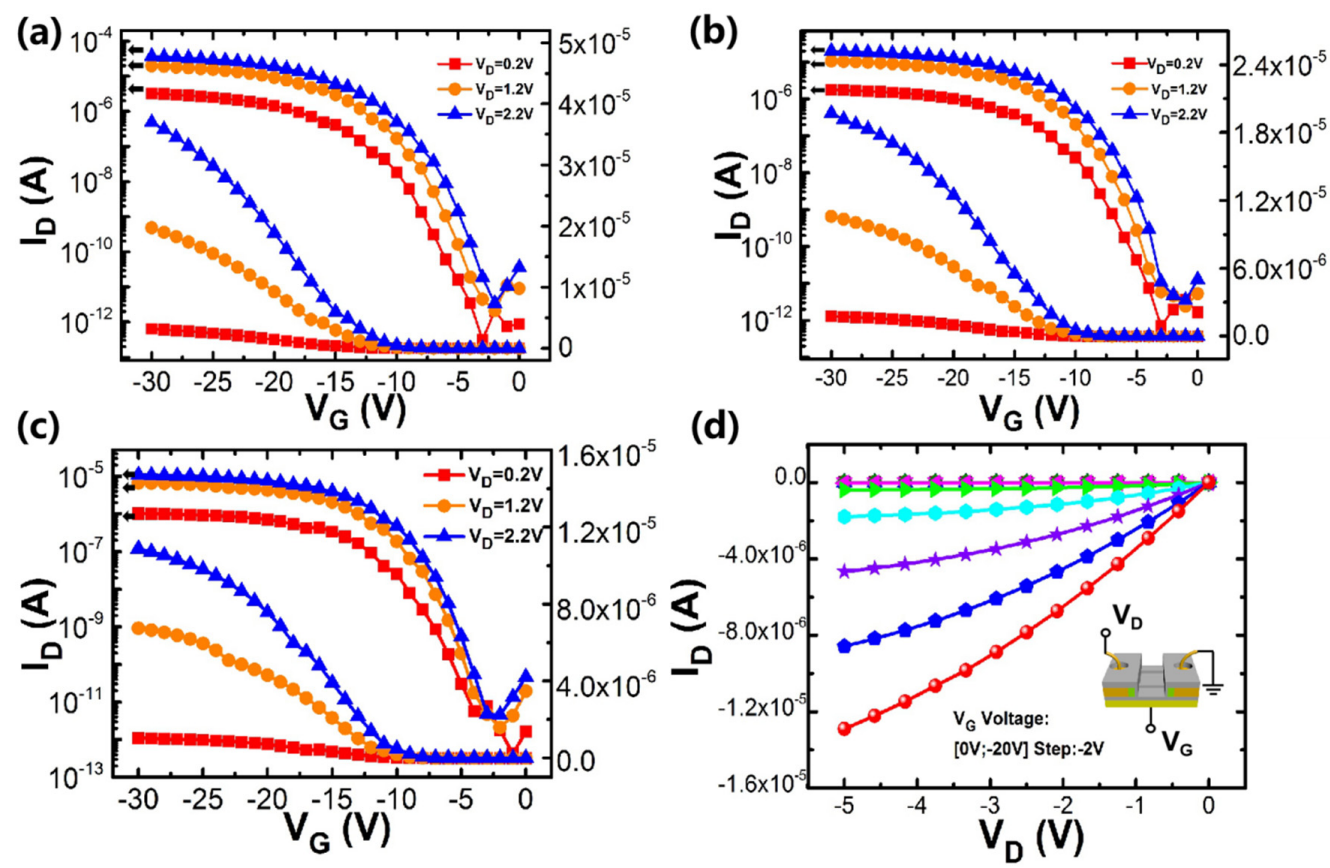

Figure 5. (a-c) $\mathrm{I}_{D}-\mathrm{V}_{\mathrm{G}}$ curves of the fabricated $5-\mu \mathrm{m}-\mathrm{L}_{\mathrm{G}}, 10-\mu \mathrm{m}-\mathrm{L}_{\mathrm{G}}$ and $15-\mu \mathrm{m}-\mathrm{L}_{\mathrm{G}} \mathrm{p}$-type poly-Si NW sensors by back bias gate voltage, (d) typical $\mathrm{I}_{\mathrm{D}}-\mathrm{V}_{\mathrm{D}}$ of the fabricated $10-\mu \mathrm{m}-\mathrm{L}_{\mathrm{G}}$ p-type poly-Si NW sensors. 
The $\mathrm{I}_{\mathrm{D}}-\mathrm{V}_{\mathrm{G}}$ and $\mathrm{I}_{\mathrm{D}}-\mathrm{V}_{\mathrm{D}}$ curves of the SOI Si NW for $5-\mu \mathrm{m}-\mathrm{L}_{\mathrm{G}}, 10-\mu \mathrm{m}-\mathrm{L}_{\mathrm{G}}$ and $15-\mu \mathrm{m}-\mathrm{L}_{\mathrm{G}}$ are shown in Figure 6, respectively. As can be seen from the images, smooth p-type MOSFET curves are achieved for the sensors fabricate at low temperature. The $\mathrm{I}_{\mathrm{on}} / \mathrm{I}_{\mathrm{off}}$ ratios of $5-\mu \mathrm{m}-\mathrm{L}_{\mathrm{G}}, 10-\mu \mathrm{m}-\mathrm{L}_{\mathrm{G}}$ and $15-\mu \mathrm{m}-\mathrm{L}_{\mathrm{G}}$ SOI Si NW devices are $1.47 \times 10^{8}, 1.29 \times 10^{7}$ and $6.34 \times 10^{4}$, respectively, and extracted values of SSs are estimated to be $686 \mathrm{mV} / \mathrm{dec}, 767 \mathrm{mV} / \mathrm{dec}$ and $1120 \mathrm{mV} / \mathrm{dec}$, respectively. Figure $6 \mathrm{~d}$ depicts the $\mathrm{I}_{\mathrm{D}}-\mathrm{V}_{\mathrm{D}}$ curves of the $10-\mu \mathrm{m}-\mathrm{L}_{\mathrm{G}}$ poly-Si NW device.
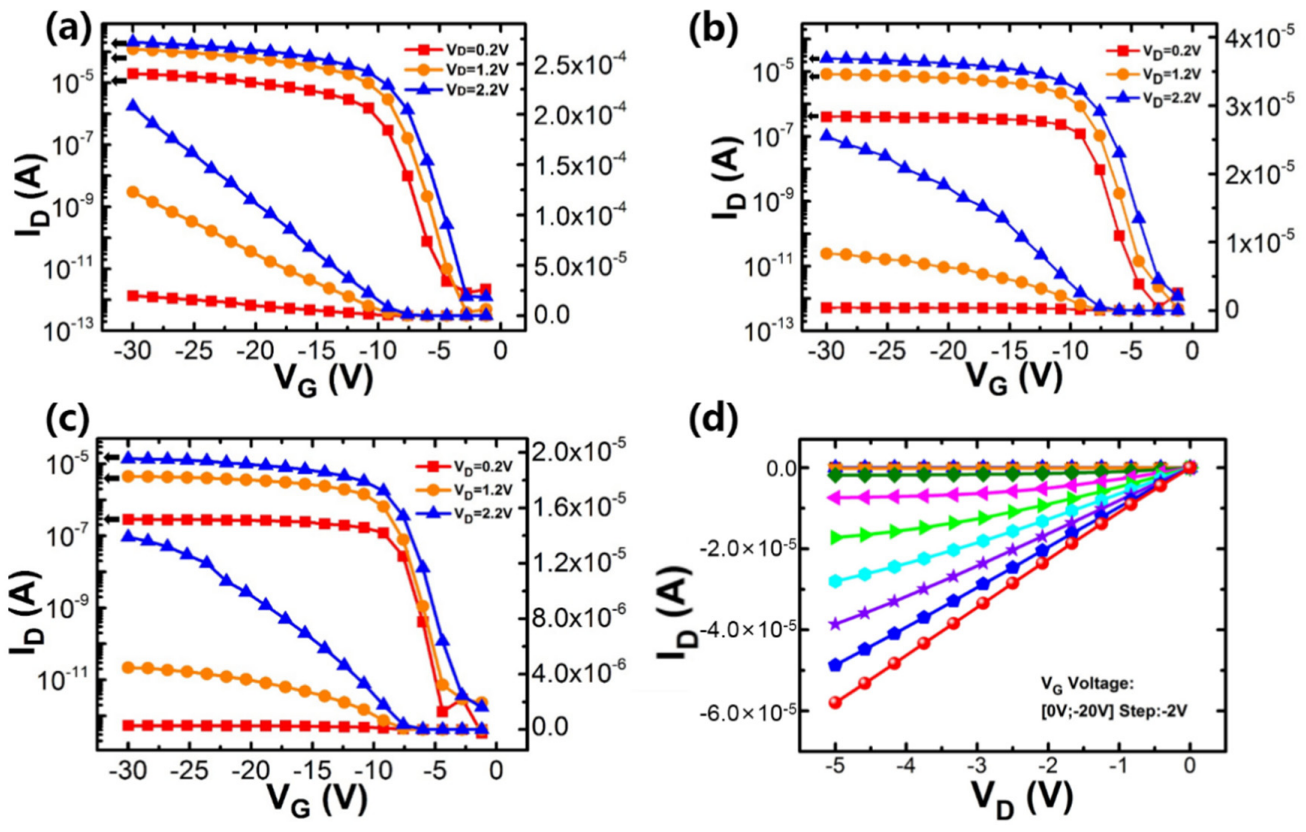

Figure 6. (a-c) typical $\mathrm{I}_{\mathrm{D}}-\mathrm{V}_{\mathrm{G}}$ curves of the fabricated $5-\mu \mathrm{m}-\mathrm{L}_{\mathrm{G}}, 10-\mu \mathrm{m}-\mathrm{L}_{\mathrm{G}}$ and $15-\mu \mathrm{m}-\mathrm{L}_{\mathrm{G}}$ p-type SOI Si NW sensors by back gate bias, respectively, (d) typical $\mathrm{I}_{\mathrm{D}}-\mathrm{V}_{\mathrm{D}}$ curves of the fabricated $10-\mu \mathrm{m}-\mathrm{L}_{\mathrm{G}}$ p-type SOI Si NW sensors.

Figure 7 shows the extracted typical parameter comparison between the poly-Si NW and SOI Si NW sensors, e.g., the threshold voltage $\left(\mathrm{V}_{\mathrm{th}}\right)$, SS, on-stage current $\left(\mathrm{I}_{\mathrm{on}}\right)$ and $\mathrm{I}_{\mathrm{on}} /$ off ratio, respectively. The $\mathrm{V}_{\mathrm{th}} \mathrm{s}$ of $5-\mu \mathrm{m}-\mathrm{L}_{\mathrm{G}}, 10-\mu \mathrm{m}-\mathrm{L}_{\mathrm{G}}$ and $15-\mu \mathrm{m}-\mathrm{L}_{\mathrm{G}}$ poly-Si NW devices are $-8.06 \mathrm{~V},-8.125 \mathrm{~V}$ and $-7.87 \mathrm{~V}$, respectively. The $\mathrm{V}_{\mathrm{th}}$ of $5-\mu \mathrm{m}-\mathrm{L}_{\mathrm{G}}, 10-\mu \mathrm{m}-\mathrm{L}_{\mathrm{G}}$ and $15-\mu \mathrm{m}-\mathrm{L}_{\mathrm{G}}$ SOI Si NW devices are $-7.67 \mathrm{~V},-7.95 \mathrm{~V}$ and $-7.8 \mathrm{~V}$, respectively. The values of $\mathrm{V}_{\mathrm{th}} \mathrm{S}$ of poly-silicon devices with different $\mathrm{L}_{\mathrm{G}} \mathrm{s}$ are similar to those of the SOI devices. The values of SSs of SOI devices are smaller than those of poly-Si devices and the $\mathrm{I}_{\mathrm{on}} / \mathrm{I}_{\text {off }}$ is also larger. The performance of SOI devices is slightly better than that of low-temperature poly-silicon devices, which is caused by the monocrystalline silicon channel with a low channel resistance. The achieved results imply that the poly-Si NW sensors could be applied for future monolithic 3D-IC application.

Figure 8 shows the typical sensing characteristics of the poly-silicon nanowire sensors by analyzing different stranded $\mathrm{pH}$ solutions. In the measurement of the $\mathrm{I}_{\mathrm{D}}-\mathrm{V}_{\mathrm{G}}$ curve and the gate voltage was swept from 0 to $-10 \mathrm{~V}$ by top solution (see Figure $8 \mathrm{a}$ inserted image). The detection principle is to convert the sensor surface potential change introduced by a different $\mathrm{pH}$ solution into the current change in the semiconductor Si NW channel. The actual amount of charges depends on the concentration of specific ions in the solution (the concentration of $\mathrm{H}^{+}$ion in the manuscripts). Therefore, the $\mathrm{pH}$ of the solutions could modulate the surface charge of the insulator/semiconducting interface consequently, resulting in a shift of the threshold voltage. The scheme of the test using the top liquid gate is shown in the inserted figure of Figure 8a. Due to the change of film surface potential of the channel, the poly-silicon nanowire sensors exhibit $V_{\text {th }}$ shifts (see Figure $8 \mathrm{a}$ ). If the added solution is acidic (alkaline), the $\mathrm{I}_{\mathrm{D}}-\mathrm{V}_{\mathrm{G}}$ curve will shift to the right (left). After adding different $\mathrm{pH}$ buffers, the real-time response of $\mathrm{I}_{\mathrm{D}}$ is shown in Figure $8 \mathrm{~b}$. Taking the buffer solution with $\mathrm{pH}=7$ as a reference, when the $\mathrm{pH}$ buffer is acidic, a positive 
charge is introduced and the current of the p-type poly-silicon nanowire sensor increases. When the $\mathrm{pH}$ buffer is alkaline, a negative charge is introduced and the current decreases. The results are consistent with the transfer curve of the p-type poly-silicon nanowire sensor increases. The extracted change values of $V_{t h}$ and $I_{D}$ as a function of $\mathrm{pH}$ values are shown in Figure $8 \mathrm{c}, \mathrm{d}$, respectively. The changes of $\mathrm{V}_{\text {th }}$ and $\mathrm{I}_{\mathrm{D}}$ have approximate linearity with the $\mathrm{pH}$ values, and the sensitivity as high as about $178 \pm 1 \mathrm{mV} / \mathrm{pH}$, which is caused by the small size in Si NW and large surface to volume ratio.
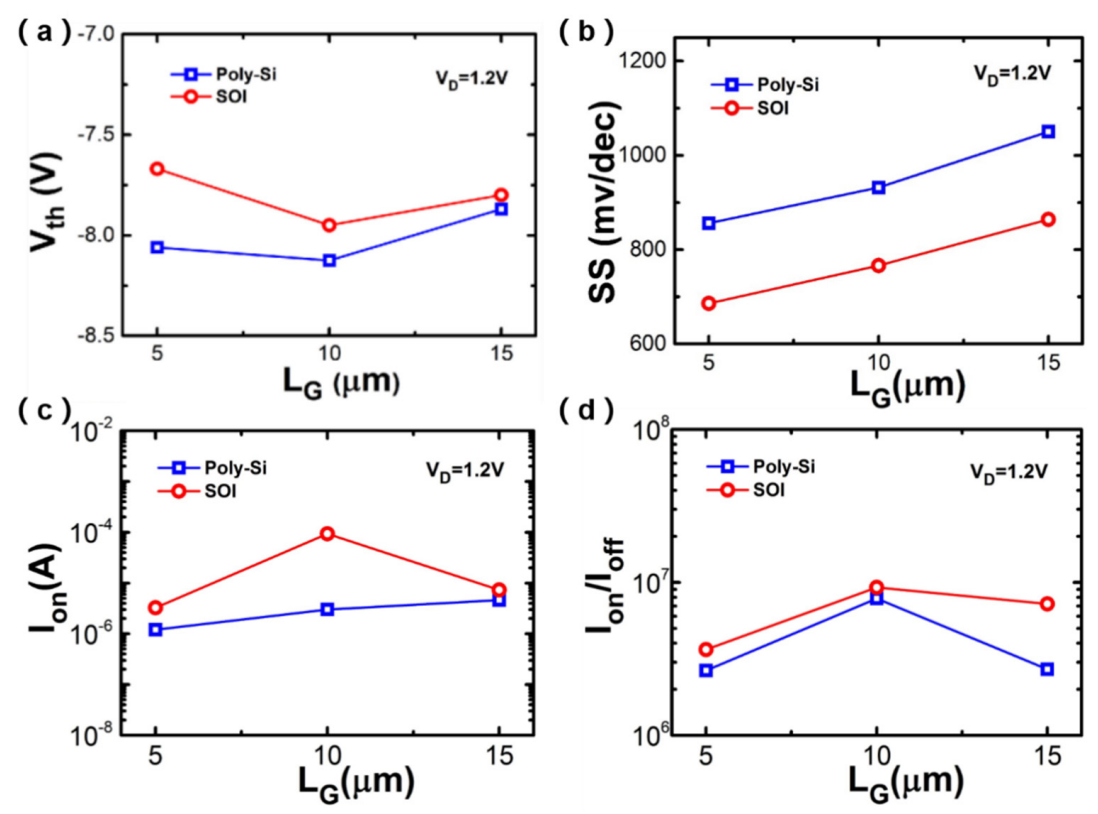

Figure 7. Comparison between low-temperature poly-silicon devices and SOI Si NW devices. (a) SS, (b) $\mathrm{V}_{\text {th }},\left(\right.$ c) $\mathrm{I}_{\text {on }}$ and (d) $\mathrm{I}_{\mathrm{on}} / \mathrm{I}_{\text {off }}$ ratio.
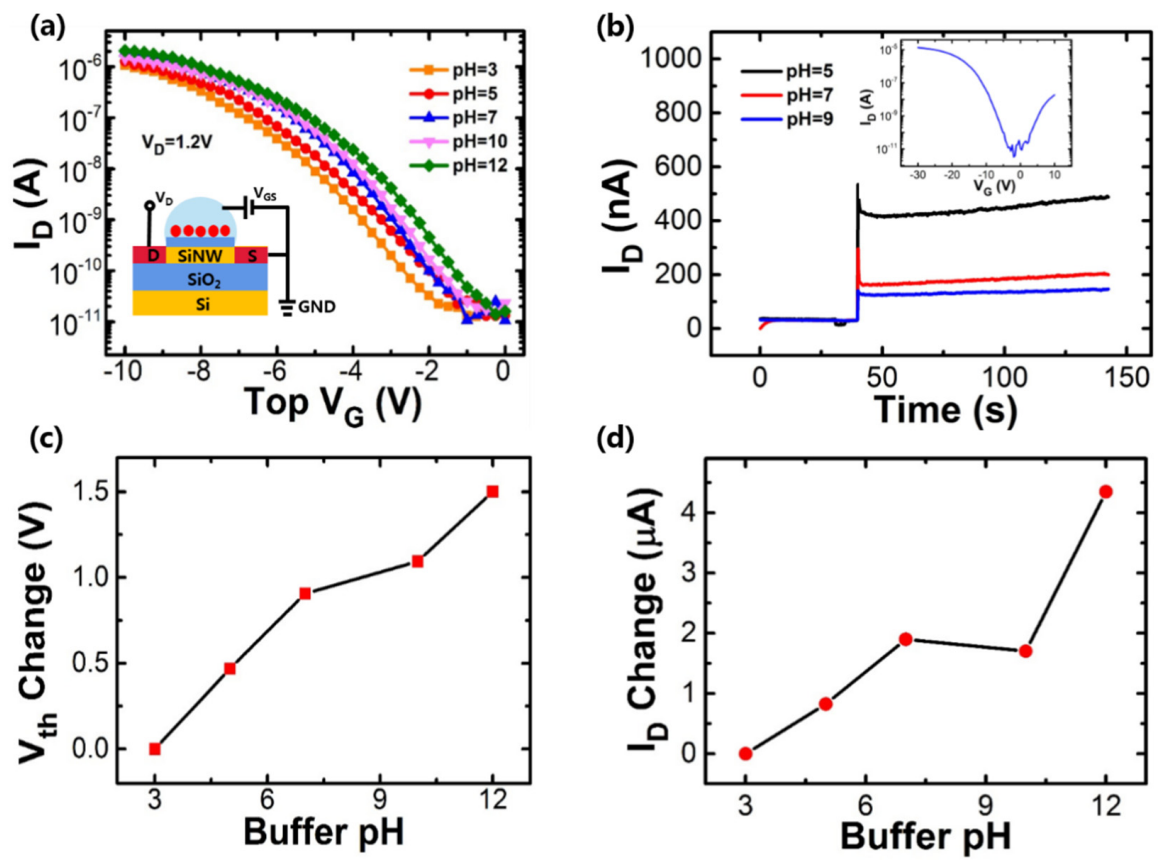

Figure 8. (a) The transfer curves of the poly-Si NW sensor by analyzing different pH solutions, (b) real-time response of $\mathrm{I}_{\mathrm{D}}$ when adding different $\mathrm{pH}$ solutions, the inserted figure the transfer curves of the bias back gate voltage, $(\mathbf{c}, \mathbf{d})$ threshold voltage and drain current change under different $\mathrm{pH}$ solutions. 
Figure 9 shows the typical sensing characteristics of the SOI nanowire sensors by analyzing different stranded $\mathrm{pH}$ solutions. In the measurement of the $\mathrm{I}_{\mathrm{D}}-\mathrm{V}_{\mathrm{G}}$ curve, the gate voltage was swept from 0 to $-4 \mathrm{~V}$ by the top solution. Figure $9 \mathrm{a}$ shows that the threshold voltage shifts with the $\mathrm{pH}$ of the solution. The extracted threshold change is linear with the $\mathrm{pH}$ of the solution (see Figure $9 \mathrm{~b}$ ). A similar trend of $\mathrm{V}_{\mathrm{th}}$ shift is obtained, but the values of changes are only about a fifth of the poly-silicon nanowire.
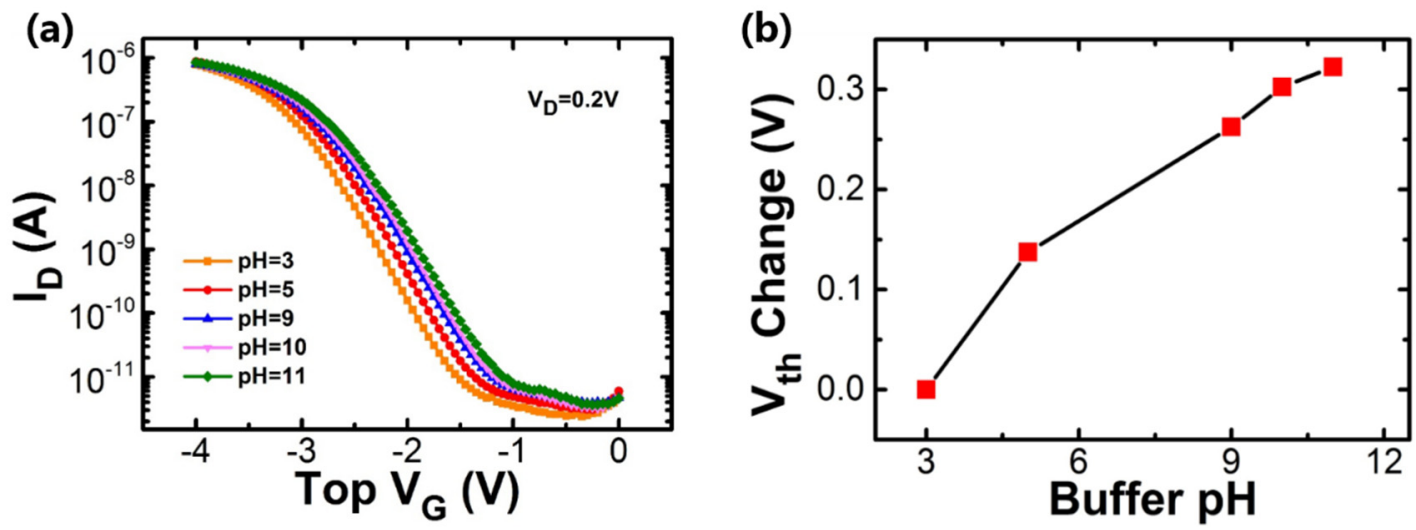

Figure 9. (a) The transfer curves of the silicon-on-insulator (SOI) sensor with different $\mathrm{pH}$ solutions, (b) threshold voltage under different $\mathrm{pH}$ solutions.

Table 1 shows system parameters comparison of the relevant reported results in recent years and our fabricated poly-silicon nanowire sensors. The SIT technique is used to form poly-silicon NW sensor arrays with $25 \mathrm{~nm}$ in width and $35 \mathrm{~nm}$ in length, which exhibits high efficiency and low cost than that of formed by EBL. Furthermore, the resistance and the device performance- the poly-silicon NW sensor is greatly improved by introducing SBSD techniques, which is attributed to achieve a larger $\mathrm{I}_{\mathrm{on}} / \mathrm{I}_{\text {off }}$ ratio and smaller values of SSs. The results indicate that the poly-silicon NWs sensor fabricated by low-temperature annealing has much better characteristics than those of the sensors prepared by other methods, which attributed to its application for future monolithic 3D-IC applications.

Table 1. A comparison of silicon nanowire sensors in recent years.

\begin{tabular}{|c|c|c|c|c|c|c|c|}
\hline & 2011 [30] & 2012 [31] & 2014 [32] & $2016[33]$ & $2020[34]$ & \multicolumn{2}{|c|}{ This Work } \\
\hline Insulation material & $\mathrm{SiO}_{2}$ & $\mathrm{SiN}_{x}$ & $\mathrm{SiO}_{2}$ & $\mathrm{SiO}_{2} / \mathrm{Si}_{3} \mathrm{~N}_{4}$ & \multicolumn{2}{|c|}{$\mathrm{SiO}_{2} / \mathrm{Si}_{3} \mathrm{~N}_{4} / \mathrm{SiO}_{2} \mathrm{SiO}_{2}$} & SOI \\
\hline Insulation thickness & $100 \mathrm{~nm}$ & - & $80 \mathrm{~nm}$ & $50 / 65 \mathrm{~nm}$ & $-/ 150 / 7 \mathrm{~nm}$ & $145 \mathrm{~nm}$ & \\
\hline NWs material & $\mathrm{Si}$ & $\mathrm{Si}$ & poly-Si & poly-Si & poly-Si & poly-Si & $\mathrm{Si}$ \\
\hline $\begin{array}{c}\text { Si NWs fabrication } \\
\text { approach }\end{array}$ & VLS & RIE & sidewall spacer & RIE & EBL & SIT & SIT \\
\hline Processing temperature & - & - & - & $600{ }^{\circ} \mathrm{C}$ & $1050^{\circ} \mathrm{C}$ & $600{ }^{\circ} \mathrm{C}$ & $600{ }^{\circ} \mathrm{C}$ \\
\hline NWs size & $\sim 90 \mathrm{~nm}$ & - & - & $\sim 40 \mathrm{~nm}$ & $40 \sim 50 \mathrm{~nm}$ & $\sim 30 \mathrm{~nm}$ & $\sim 30 \mathrm{~nm}$ \\
\hline $\mathrm{L}_{\mathrm{G}}$ & - & - & $100 \mathrm{~nm}$ & $10 \mu \mathrm{m}$ & $400 \mathrm{~nm}$ & $10 \mu \mathrm{m}$ & $10 \mu \mathrm{m}$ \\
\hline $\mathrm{I}_{\mathrm{on}} / \mathrm{I}_{\mathrm{off}}$ & $\sim 10^{5}$ & $\sim 10^{4}$ & - & $2.03 \times 10^{5}$ & $2.5 \times 10^{5}$ & $2.84 \times 10^{6}$ & $1.29 \times 10^{7}$ \\
\hline $\mathrm{SS}(\mathrm{mV} / \mathrm{dec})$ & 2500 & $2300-3000$ & - & 975 & 1030 & 965 & 767 \\
\hline $\mathrm{V}_{\text {th }}$ change $(\mathrm{V})$ & - & - & 0.087 & 0.0437 & - & 0.178 & 0.0688 \\
\hline
\end{tabular}

\section{Conclusions}

In summary, low cost poly-Si NW sensors arrays are fabricated through an advanced SIT process with high efficiency than that formed by electron beam lithography, and the morphology of Si NW is well controlled with small sizes. Furthermore, a low-temperature flow $\left(600{ }^{\circ} \mathrm{C}\right)$ with silicide and implantation is designed and carried out. Benefiting from the silicide and isolation processes, the poly-Si NW FET sensors show six orders of magnitude in switching ratio and a SS of $965 \mathrm{mV} / \mathrm{dec}$, which is similar to the counterpart of the SOI Si NW sensor. In addition, the poly-Si NW FET sensors 
show the $\mathrm{V}_{\text {th }}$ shift as high as about $178 \pm 1 \mathrm{mV} / \mathrm{pH}$, which is five times larger than that of the SOI Si NW sensors. Therefore, the design and fabricated poly-Si NW sensor arrays approach provides a good option for its potential application of the monolithic 3D-ICs in the future.

Author Contributions: Conceptualization, S.T., Q.Z., J.Z., J.Y. (Jiang Yan); methodology, S.T., Q.Z., J.Z., J.L., S.W., Y.W., Z.Z., Q.W., H.Y., J.Y. (Jianglan Yang), M.F., S.Z., E.X.; data curation, S.T. and Q.Z.; writing original draft preparation, S.T.; writing review and editing, S.T., Q.Z. and Z.Z.; supervision, W.W., J.Y. (Jiang Yan) and H.T.; project administration, W.W.; funding acquisition, W.W. All authors have read and agreed to the published version of the manuscript.

Funding: This work was supported in part by the Natural Science Foundation of Beijing, China (4182021), the Science and technology program of Beijing Municipal Science and Technology Commission under grants Z201100006820084 and Z201100004220001, in part by the National Key Project of Science and Technology of China under grant 2017ZX02301007-001 and 2017ZX02315001-001, the Youth Innovation Promotion Association, Chinese Academy of Sciences under grant Y9YQ01R004, the National Natural Science Foundation of China under grants 61874002 and 61904194, and 6187032253, and in part by the Opening Project of Key Laboratory of Microelectronic Devices and Integrated Technology, Institute of Microelectronics, Chinese Academy of Sciences under Grant Y9YS05X002 and E0YS01X001.

Acknowledgments: We thank the Integrated Circuit Advanced Process Center (ICAC) at the Institute of Microelectronics of the Chinese Academy of Sciences for the devices fabricated on their advanced $200 \mathrm{~mm}$ CMOS platform.

Conflicts of Interest: The authors declare no conflict of interest.

\section{References}

1. Qin, Y.; Liu, D.; Zhang, T. Ultrasensitive Silicon Nanowire Sensor Developed by a Special Ag Modification Process for Rapid NH3 Detection. ACS Appl. Mater. Interfaces 2017, 9, 28766-28773. [CrossRef]

2. Jin, Y.; Gao, A.; Jin, Q.H.; Li, T.; Wang, Y.; Zhao, J.-L. Ultra-sensitive and selective Detection of Mercury Ion $\left(\mathrm{Hg}^{2+}\right)$ using free-standing Silicon Nanowire Sensors. Nanotechnology 2018, 29, 135501. [CrossRef]

3. Yu, X.G.; Li, Y.Q.; Zhu, W.B.; Huang, P.; Wang, T.; Hu, N.; Fu, S.-Y. A wearable strain sensor based on a carbonized nano-sponge/silicone composite for human motion detection. Nanoscale 2017, 9, 6680-6685. [CrossRef]

4. Römhildt, L.; Zörgiebel, F.; Ibarlucea, B.; Vahdatzadeh, M.; Baraban, L.; Cuniberti, G.; Pregl, S.; Weber, W.M.; Mikolajick, T.; Opitz, J. Human $\alpha$-thrombin detection platform using aptamers on a silicon nanowire field-effect transistor. In Proceedings of the Power and Timing Modeling, Optimization and Simulation (PATMOS), 2017 27th International Symposium on IEEE, Thessaloniki, Greece, 25-27 September 2017; pp. 1-4.

5. Besteman, K.; Lee, J.; Wiertz, F.G.M.; Heering, H.A.; Dekker, C. Enzyme-Coated Carbon Nanotubes as Single-Molecule Biosensors. Nano Lett. 2003, 3, 727-730. [CrossRef]

6. Cui, Y.; Wei, Q.; Park, H.; Lieber, C.M. Nanowire nanosensors for highly sensitive and selective detection of biological and chemical species. Science 2001, 293, 1289-1292. [CrossRef]

7. Hahm, J.; Lieber, C.M. Direct Ultrasensitive Electrical Detection of DNA and DNA Sequence Variations Using Nanowire Nanosensors. Nano Lett. 2004, 4, 51-54. [CrossRef]

8. Patolsky, F.; Zheng, G.; Hayden, O.; Lakadamyali, M.; Zhuang, X.; Lieber, C.M. Electrical detection of single viruses. Proc. Natl. Acad. Sci. USA 2004, 101, 14017-14022. [CrossRef]

9. Lee, J.K.; Wang, I.; Huang, C.H.; Chen, Y.-F.; Huang, N.-T.; Lin, C.-T. Pre-Clinical Tests of an Integrated CMOS Biomolecular Sensor for Cardiac Diseases Diagnosis. Sensors 2017, 17, 2733. [CrossRef]

10. D'Andrea, C.; Lo Faro, M.J.; Bertino, G.; Ossi, P.M.; Neri, F.; Trusso, S.; Musumeci, P.; Galli, M.; Cioffi, N.; Irrera, A.; et al. Decoration of silicon nanowires with silver nanoparticles for ultrasensitive surface enhanced Raman scattering. Nanotechnology 2016, 27, 375603. [CrossRef]

11. Fazio, B.; D’Andrea, C.; Foti, A.; Messina, E.; Irrera, A.; Donato, M.G.; Villari, V.; Micali, N.; Maragò, O.M.; Gucciardi, P.G. SERS detection of Biomolecules at Physiological pH via aggregation of Gold Nanorods mediated by Optical Forces and Plasmonic Heating. Science 2016, 6, 26952. [CrossRef]

12. Gogoi, P. Thermally deposited Ag-doped CdS thin film transistors with high-k rare-earth oxide $\mathrm{Nd}_{2} \mathrm{O}_{3}$ as gate dielectric. Semiconductors 2013, 47, 341-344. [CrossRef] 
13. Zhu, W.J.; Tamagawa, T.; Gibson, M.; Furukawa, T. Effect of $\mathrm{Al}$ inclusion in $\mathrm{HfO}_{2}$ on the physical and electrical properties of the dielectrics. IEEE Electr. Device L 2002, 23, 649-651. [CrossRef]

14. Serena, R.B.; Dipti, R.; Wouter, O.; César, P.G. High performance Fin-FET electrochemical sensor with high-k dielectric materials. Sens. Actuators B Chem. 2020, 303, 127215.

15. Chiou, Y.K.; Chang, C.H.; Wang, C.C.; Lee, K.Y.; Wu, T.B.; Kwo, R.; Hong, M. Effect of Al incorporation in the thermal stability of atomic-layer-deposited $\mathrm{HfO} 2$ for gate dielectric applications. J. Electrochem. Soc. 2007, 154, G99-G102. [CrossRef]

16. Li, X.F.; Liu, X.J.; Zhang, W.Q.; Fu, Y.Y.; Li, A.D.; Li, H.; Wu, D. Comparison of the interfacial and electrical properties of HfAlO films on Ge with $\mathrm{S}$ and GeO2 passivation. Appl. Phys. Lett. 2011, 98, 162903. [CrossRef]

17. Song, Z.R.; Cheng, X.H.; Zhang, E.X.; Xing, Y.; Yu, Y.; Zhang, Z.; Wang, X.; Shen, D. Influence of preparing process on total-dose radiation response of high-k Hf-based gate dielectrics. Thin. Solid Film. 2008, 517, 465-467. [CrossRef]

18. Dalapati, G.K.; Sridhara, A.; Wong, A.S.W.; Chia, C.K. Plasma nitridation of $\mathrm{HfO}_{2}$ gate dielectric on p-GaAs substrates. ECS Trans. 2008, 16, 387-392. [CrossRef]

19. McNeill, D.W.; Bhattacharya, S.; Wadsworth, H.; Ruddell, F.H.; Mitchell, S.J.N.; Armstrong, B.M.; Gamble, H.S. Atomic layer deposition of hafnium oxide dielectrics on silicon and germanium substrates. J. Mater. Sci. Mater. Electron. 2007, 19, 119-123. [CrossRef]

20. Tomida, K.; Popovici, M.; Opsomer, K.; Menou, N. Non-linear dielectric constant increase with Ti composition in high-k ALD-HfTiOx films after O2 crystallization annealing. Iop Conf. Ser. Mater. Sci. Eng. 2010, 8, 012023. [CrossRef]

21. Ahn, J.-H.; Kim, J.-Y.; Seol, M.-L.; Baek, D.J.; Guo, Z.; Kim, C.-H.; Choi, S.-J.; Choi, Y.-K. A pH sensor with a double-gate silicon nanowire field-effect transistor. Appl. Phys. Lett. 2013, 102, 083701. [CrossRef]

22. Vu, X.T.; Eschermann, J.F.; Stockmann, R.; GhoshMoulick, R.; Offenhäusser, A.; Ingebrandt, S. Top-down processed silicon nanowire transistor arrays for biosensing. Phys. Status Solidi A Appl. Res. 2009, 206, 426-434. [CrossRef]

23. Galina, P.; Denis, P.; Vladimir, K.; Vitaly, G. Biosensor based on a silicon nanowire field-effect transistor functionalized by gold nanoparticles for the highly sensitive determination of prostate specific antigen. Biosens. Bioelectron. 2017, 88, 283-289.

24. Fenouillet-Beranger1, C.; Batude1, P.; Brunet1, L.; Mazzocchi1, V. Recent advances in low temperature process in view of 3D VLSI integration. In Proceedings of the 2016 IEEE SOI-3D-Subthreshold Microelectronics Technology Unified Conference, Burlingame, CA, USA, 10-13 October 2016; pp. 1-3.

25. Qingzhu, Z.; Hailing, T.; Huaxiang, Y.; Feng, W.; Hongbin, Z.; Qianhui, W.; Zhaohao, Z.; Wenwu, W. Si Nanowire Biosensors Using a FinFET Fabrication Process for Real Time Monitoring Cellular Ion Actitivies. IEDM 2018, 18, 679-682.

26. Zafar, S.; D’Emic, C.; Jagtiani, A.; Kratschmer, E.; Miao, X.; Zhu, Y.; Mo, R.; Sosa, N.; Hamann, H.F.; Shahidi, G.; et al. Silicon Nanowire Field Effect Transistor Sensors with Minimal Sensor-to-Sensor Variations and Enhanced Sensing Characteristics. ACS Nano 2018, 12, 6577-6587. [CrossRef]

27. Zhang, N.; Zhang, Z.; Zhang, Q.; Wei, Q.; Zhang, J.; Tang, S.; Lv, C.; Wang, Y.; Zhao, H.; Wei, F.; et al. $\mathrm{O}_{2}$ plasma treated biosensor for enhancing detection sensitivity of sulfadiazine in a high-k $\mathrm{HfO}_{2}$ coated silicon nanowire array. Sens. Actuators B Chem. 2020, 306, 127464. [CrossRef]

28. Guo-Jun, Z.; Li, Z.; Min, J.H.; Zhan, H.H.L.; Guang, K.I.T.; Eu-Jin, A.L.; Tae, G.K.; Yu, C. Silicon nanowire biosensor for highly sensitive and rapid detection of Dengue virus. Sens. Actuators B Chem. 2010, 146, 138-144.

29. Guo-Jun, Z.; Kevin, T.C.C.; Henry, Z.H.L.; Joon, M.H.; Ignatius, G.K.T.; Andy, E.-J.L.; Minkyu, J. Multiplexed detection of cardiac biomarkers in serum with nanowire arrays using readout ASIC. Biosens. Bioelectron. 2012, 35, 218-223.

30. Wong, W.S.; Raychaudhuri, S. Hybrid Si Nanowire/Amorphous Silicon FETs for Large-Area Image Sensor Arrays. Nano Lett. 2011, 11, 2214-2218. [CrossRef]

31. Hakim, M.M.A.; Lombardini, M.; Sun, K. Thin Film Polycrystalline Silicon Nanowire Biosensors. Nano Lett. 2012, 12, 1868-1872. [CrossRef] 
32. Salaün, A.-C.; Pichon, L.; Wenga, G. Polysilicon nanowires FET as highly-sensitive pH-sensor:modeling and measurements. Procedia Eng. 2014, 87, 911-914. [CrossRef]

33. Yen, L.C.; Pan, T.M.; Lee, C.H.; Chao, T.S. Label-free and real-time detection of ferritin using a horn-like polycrystalline-silicon nanowire field-effect transistor biosensor. Sens. Actuators B 2016, 230, 398-404. [CrossRef]

34. Chen, G.; Yu, B.; Li, X.; Dong, X.; Xu, X.; Li, Z.; Huang, R.; Li, M. A photomemory by selective-assembling hybrid porphyrin-silicon nanowire field-effect transistor. Sci. China Inf. Sci. 2020, 63, 169401:1-169401:3. [CrossRef]

Publisher's Note: MDPI stays neutral with regard to jurisdictional claims in published maps and institutional affiliations.

(C) 2020 by the authors. Licensee MDPI, Basel, Switzerland. This article is an open access article distributed under the terms and conditions of the Creative Commons Attribution (CC BY) license (http://creativecommons.org/licenses/by/4.0/). 